\title{
EDUCAÇÃO AMBIENTAL NA ESCOLA: ATRAVÉS DA CONSTRUÇÃO DE ESPAÇOS REFLEXIVOS DE PROBLEMATIZAÇÃO SOBRE O TEMA
}

\author{
Gabriella Eldereti Machado ${ }^{1}$ \\ Bruna Roque Mazzaro ${ }^{2}$ \\ Janaína Balk Brandão ${ }^{3}$ \\ Katia Messa ${ }^{4}$
}

\section{INTRODUÇÃO}

A presente escrita é fruto das atividades desenvolvidas desde o ano de 2015 no Projeto de Educação Ambiental "Escola Responsável", que visa a partir da construção coletiva de um processo de conscientização ambiental nas escolas do município de Alegrete/RS, objetivando atentar para a problemática da correta destinação dos resíduos gerados no ambiente escolar, bem como incentivar alternativas para (re)utilização desses resíduos, como por exemplo, na confecção de hortas suspensas com garrafas PET.

No ano de 2015 abrangeu-se 40 professores, 10 funcionários das escolas e 300 alunos da cidade de Alegrete, para este ano será ampliado o número de participantes. Além de parcerias com as Secretárias do Meio Ambiente e da Educação e Cultura do município, integrando a Semana Municipal de Meio Ambiente de Alegrete com ações de conscientização da comunidade; elaboração de materiais didáticos e folder que aborda a problemática ambiental.

\footnotetext{
${ }^{1}$ Química Licenciada (IF Farroupilha Campus Alegrete), Discente dos cursos de Especialização em Educação Ambiental e Ciência e Tecnologia em Alimentos na Universidade Federal de Santa Maria. Bolsista no Projeto de Extensão "Escola Responsável", registrado no Gabinete de Projeto com o número: 039554. gabriellaelderete@hotmail.com

${ }^{2}$ Discente do Curso de Engenharia Florestal (UFSM), colaboradora no Projeto de Extensão "Escola Responsável". brunaroquemazzaro@hotmail.com

3 Agrônoma (UFSM), Mestrado e Doutorado em Extensão Rural (UFSM). Docente do departamento de Educação Agrícola e Extensão Rural da UFSM, coordenadora do Projeto de Extensão "Escola Responsável". janainabalkbrandao@hotmail.com

${ }^{4}$ Agrônoma da Secretaria de Meio Ambiente de Alegrete/RS.
} 


\section{METODOLOGIA}

Para dinamizar a realização do projeto iniciou-se por um diagnóstico, por meio de um questionário com 18 perguntas, a fim de conhecer a percepção dos professores e funcionários com relação à destinação dos resíduos e as ações de Educação Ambiental (EA) já desenvolvidas nas escolas. Após, organizou-se espaços de diálogos problematizadores com relação a atual postura adotada e as exigências legais em vigor; e a construção por meio de um Planejamento Estratégico Participativo das ações a serem desenvolvidas, resultando em uma agenda ambiental com intuito de atender as demandas existentes.

O Planejamento Estratégico Participativo possui um caráter construtivista e participativo, baseado nas contribuições de Silva (2001) apresentadas com a sistematização dos Onze passos do PEP. O Planejamento Estratégico Participativo (PEP) insere-se no contexto escolar como uma metodologia que orienta e analisa a realidade, com o propósito de sustentar as decisões e ações a serem realizadas, potencializando a gestão escolar (LÜCK, 2000). Para que o PEP tenha um sentido organizacional de resultados positivos, é necessário que algumas estratégias sejam efetivadas no âmbito escolar. Como forma facilitadora para que ocorra este processo, são apontadas por Lück (2005, p. 20) as seguintes estratégias: criar uma visão de conjunto associada a uma ação de cooperação; promover um clima de confiança; valorizar as capacidades e aptidões dos participantes; associar esforços, quebrar arestas, eliminar divisões e integrar esforços; estabelecer demanda de trabalho centrado nas ideias e não em pessoas; desenvolver a prática de assumir responsabilidades em conjunto.

$\mathrm{Na}$ Escola 1, realizou-se em um momento inicial a demonstração da proposta para o grupo, percebendo a clareza desta Fase avança-se para a dinâmica do sétimo passo, pois a Escola já possuía uma trajetória de trabalho em diversas ações de EA. Resultando no objetivo final para todos os participantes a ser almejado: sendo a Consolidar a EA na escola.

A Escola 2, foram seguidos todos os onze passos sugeridos por Silva (2001) pois o grupo dispunha de um tempo maior para o PEP e as iniciativas já existentes estavam mais dispersas. Iniciando pela indagação 
sobre os problemas enfrentados, estimulando o pensamento em relação à situação atual, priorizando problemas mais importantes dentro da escola. Delimitando as ações a serem efetuadas e concretizadas.

\section{RESULTADOS E DISCUSSÃO}

Foram colocadas em prática as seguintes propostas na Escola 1: a reutilização de materiais como brinquedos através de uma oficina e óleo de cozinha; produção de uma horta suspensa e coletiva atendendo a demanda dos alunos e comunidade; realização de compostagem; fazer um projeto paisagístico; organização de uma gincana ambiental; e coleta seletiva; além de preservação e criação de áreas de lazer. A partir das ações estabeleceram-se coletivamente prazos a serem cumpridos, e os responsáveis pela realização das ações, além de recursos (pessoais ou materiais) necessários.

O plano de ação realizado pela Escola 2, propôs a exposição de fotos e solicitação de limpeza do ambiente escolar aos órgãos responsáveis, além da execução das ações de separação do lixo e a correta destinação dos mesmos para reciclagem. Nas duas Escolas participantes enfatiza-se o notório interesse dos professores em contribuir na execução da proposta, mostrandose abertos e predispostos a colaborar, expressando suas preocupações pela temática e a possibilidade de permear o conteúdo em todas as disciplinas da grade curricular, contextualizando com a realidade onde a escola está inserida. Visto que são eles que estarão em contato direto com os alunos e terão a responsabilidade de levar os projetos adiante. Logo, uma fase de sensibilização auxilia no fazer surgir o sentimento de pertencimento.

Para chegar-se a estas concretizações de ações, foram considerados alguns fatores prévios na preparação das escolas, como aponta Andrade (2000), entre eles: tamanho da escola, número de alunos e de professores, predisposição destes professores em passar por um processo de treinamento (e desenvolvimento das atividades propostas), vontade da diretoria de realmente implementar um projeto na área ambiental. Além destes fatores, direciona para que os processos sejam realizados de forma conjunta, cooperada, onde todos os envolvidos estejam de uma forma ou de outra, interligados. 
Assim, se faz necessário entender à aprendizagem ambiental como um saber pedagógico, que para Vargas (2010) constitui uma construção analítica e interpretativa dos processos de elaboração de sentidos comuns e conhecimentos públicos sobre a sustentabilidade ecológica, social, cultural e econômica do planeta. Essas são interfaces inerentes ao desenvolvimento de estratégias e ações de ensino. Ou, ainda, de formulações e proposições para a área ambiental. Dito isso, se pode inferir que a EA é um processo de educação, que deve ser desenvolvido na Escola como prática pedagógica, envolvendo todos os contextos sociais, econômicos e culturais que ali residem.

Além disso, para Tozoni; Reis (2006), de modo geral, a sensibilização e a conscientização fazem parte de um processo de ação concreta e reflexão e ao incorporar o tema ambiental, o processo da educação conscientizadora tem como objetivo a transformação das relações entre os sujeitos e desses com o ambiente, estabelecidas pela história das relações sociais.

Até o momento foram obtidas avaliações referentes ao PEP com resultados $100 \%$ positivos nas Escolas 1 e 2, superando as expectativas dos moderadores, podendo-se destacar observações como: "Metodologia muito criativa e democrática"; "Foi muito interessante à forma de planejar o projeto. Essa forma esportiva facilita a visualização das propostas. Acredito que as ações são possíveis de serem realizadas."; "Adorei a metodologia e sistematização do projeto."; "Parabéns! Em primeiro lugar pela grande iniciativa, pelo projeto pensando no futuro de todos nós, pela organização e obrigada pela oportunidade.";"Muito bom um momento de reflexão, que paramos para pensar no que está acontecendo ao nosso redor."; "Trabalho excelente, metodologia maravilhosa e ótimo preparo da mediadora."; "A maneira como conduziste a apresentação da proposta foi agradável e dinâmica."; "Muito bom, é sempre motivador trabalhar com propostas coletivas e aprender como fazê-las. Estamos gratas a vocês!"; "Um momento de reflexão que chegamos num determinado momento, maravilhoso."; "Metodologia usada foi ótima, isto é, adequada pedagogicamente. Agradecemos a parceria. Parabéns pelo trabalho.". 


\section{CONCLUSÃO}

Pode-se concluir que o Projeto está abrangendo de forma positiva suas demandas iniciais através dos processos educativos relacionados à temática ambiental e mudança na forma de tratar os resíduos por meio da concretização das ações que serão realizadas nas Escolas, além de possibilitar um acompanhamento avaliativo do que está sendo feito durante a sistematização das etapas.

Em 2016 além das três escolas já participantes, pretende-se inserir de forma sistemática acadêmicos de graduação que cursam as disciplinas de Gestão Ambiental dos cursos de Zootecnia e Ciência e Tecnologia em Alimentos da UFSM, a fim de propiciar a troca de saberes entre acadêmicos e comunidade escolar sendo uma forma de interação que deve existir entre a universidade e a comunidade. Através de Projetos que envolvam diversos âmbitos educativos, torna-se real o processo de socialização do conhecimento, por meio desta relação entre a Universidade e a sociedade.

\section{REFERÊNCIAS}

ANDRADE, D. F. Implementação da Educação Ambiental em escolas: uma reflexão. In: Fundação Universidade Federal do Rio Grande. Revista Eletrônica do Mestrado em Educação Ambiental, v. 4.out/nov/dez 2000.

LÜCK, H. A aplicação do planejamento estratégico na escola. Revista Gestão em Rede, no. 19, abril, 2000, p. 8-13. RJ: Vozes, 2005.

A escola Participativa: o trabalho do gestor escolar. Petrópolis,

SILVA, M. J. P. Onze passos do planejamento estratégico participativo. In: Markus Brose (org) Metodologia Participativa. Uma introdução a 20 instrumentos. Porto Alegre: Tomo Editorial, 2001.pp.161-176.

TOZONI-REIS, M. F. de C. Temas ambientais como "temas geradores": contribuições para uma metodologia educativa ambiental crítica, transformadora e emancipatória. Educ. rev. [online]. 2006, n.27, pp. 93-110. ISSN 0104-4060. Disponível em: http://dx.doi.org/10.1590/S010440602006000100007, Acesso em 02 de outubro de 2015.

VARGAS, S. A complexidade ambiental / Enrique Leff, (coord.); tradução de Eliete Wolff. - 2 ed. - São Paulo: Cortez, 2010. 